\title{
Correction to: Refugee Oral Health: A Global Survey of Current Policies and Practices
}

\author{
Elham Kateeb ${ }^{1} \oplus \cdot$ Marc Sintes $^{2} \cdot$ Sean Taylor ${ }^{2}$
}

Published online: 17 December 2021

○) Springer Science+Business Media, LLC, part of Springer Nature 2021

\section{Correction to: Journal of Immigrant and Minority Health https://doi.org/10.1007/s10903-021-01285-6}

The original version of this article unfortunately contained errors in in-text reference citation and in reference list.

In last sentence of Background section and Conclusion section, the in-text reference citation should be [15] instead of [16]. Thus, the last sentences should read as follows

In background section:

The guide raises awareness about the burden of oral diseases among refugees and provides a step by step plan to advocate for better oral health in this vulnerable population [15].

In conclusion section:
Success stories, best practices and a step-by-step roadmap to advocate for better oral health among refugees were presented in the FDI Refugee Oral Health Advocacy Guide [15] and can be used to inform and inspire such initiatives.

And in Reference 15, the web link provided earlier is broken and the correct link is https://www.fdiworlddental.org/ sites/default/files/2021-02/Promoting\%20Oral\%20Health\% 20for\%20Refugees\%20-\%20An\%20Advocacy\%20Guide.pdf The original article has been corrected.

Publisher's Note Springer Nature remains neutral with regard to jurisdictional claims in published maps and institutional affiliations.

The original article can be found online at https://doi.org/10.1007/ s10903-021-01285-6.

Elham Kateeb

ekateeb@staff.alquds.edu; elhame20@gmail.com

1 Oral Health Research and Promotion Unit, College of Dentistry, Al-Quds University, University Main St, P.O Box 89, Jerusalem, Palestine

2 Education and Public Health Department, FDI World Dental Federation FDI, Geneva, Switzerland 